\title{
A Citation-Based Patent Evaluation Framework to Reveal Hidden Value and Enable Strategic Business Decisions
}

\author{
Derek Smith
}

\author{
"The value of patents as competitive weapons and") \\ intelligence tools becomes most evident in the day-to- \\ day transaction of business.
}

\author{
Kevin G. Rivette and David Kline \\ Authors of Rembrandts in the Attic: \\ Unlocking the Hidden Value of Patents
}

\begin{abstract}
Patent evaluation methodologies enable firms to make informed strategic business decisions by associating and revealing hidden information surrounding a patent. However, the value of a patent depends on a firm's capabilities and strategic direction; therefore, a patent evaluation requires the information to be properly related and aligned with a particular business consideration. This article reviews the literature on citation-based patent evaluation methodologies and develops a framework to help managers and entrepreneurs identify strategic groups of business considerations. The framework shows how categories of information can be interrelated to different strategic groups of business considerations, thereby providing a competitive advantage to the evaluating firm. The article includes recommendations for managers and entrepreneurs to help them make citation-based patent evaluation an ongoing business practice to enable strategic decision making.
\end{abstract}

\section{Introduction}

A patent can bring several well-known forms of potential value to a firm, primarily through the option for a 20 -year monopoly to a patented technology. The monopoly represents other forms of value such as exclusive usage rights, licensing opportunities (with potential royalties), and proceeds from any future sale of the patent. These and numerous other forms of patent value can be categorized as bringing defensive, offensive, strategic/business, and technology leadership value to firms (de Wilton, 2011).

However, patents are expensive, and not all patents bring value. Moreover, a given patent may not have the same value to all firms, depending on their capabilities and strategic direction. So, whether a firm is evaluating its own patent portfolio or is considering a purchase involving intellectual property, the challenge lies in identifying the potential value of a patent to the firm.
Of particular importance are the hidden insights that relate to the strategic direction of the firm, because they may suggest new opportunities or business decisions, either now or in the future.

A patent evaluation allows managers or entrepreneurs to reveal insights concerning the value of a patent, or a portfolio of patents, within the context of their own firm. Patent evaluation methodologies generally assess three interrelated aspects of a patent: i) the new technology protected by a patent; ii) the old technology known before the patent; and iii) the associated commercial business information. Such an assessment ensures that other information associated with the patent, beyond the new technology solely described in the patent, is applied and considered in the assessment.

A key input to many patent evaluation methodologies examines the old technology information in the form of a prior art citations. Citations are a list of old techno- 


\section{A Citation-Based Patent Evaluation Framework}

\section{Derek Smith}

logy that the patent office used to ensure that only new and non-obvious inventions become a granted patent. The government patent examiner seeks to identify and apply relevant citations against the patent application to ensure that old, uninventive technology does not issue as a patent. Citations may include both patent documents and academic literature. A citation-based patent evaluation may also consider other patent-related and business-related information, which may reveal strategic considerations such as potential joint ventures, mergers, or acquisitions.

The problem is, how can an entrepreneur or manager deal with the initial complexities of a patent evaluation? What are the business issues and potential opportunities facing a firm? What type of information is required for a specific business consideration? How does a firm relate the business issues and potential opportunities with relevant information to reveal insight that leads to better decisions concerning issues and opportunities?

Previous research on citation-based patent evaluation methodologies has focused on a single business issue or opportunity that may be grouped into the categories of strategic partnerships, identifying strategic innovation, or inventions and strategic linkages between firms and people. The information required is narrowly selected for that issue or opportunity. The previous approaches result in a fragmented and narrow view of evaluation requirements, strategic business considerations, and relevant information.

Understanding a larger group of strategic business options, issues, and opportunities both for and against a firm can lead to determining the potential value on a broader scale of evaluation methodologies. Understanding the information requirements enables entrepreneurs or managers to proactively plan and gather information to evaluate strategic business issues and opportunities. For example, an entrepreneur or manager could :

- select a business issue or opportunity from the group and identify the associated relevant information

- proactively track and gather this relevant information over time on an ongoing basis as part of a strategic business practice to ensure they have the relevant information when it is needed to evaluate the issue or opportunity

- be prepared to execute a patent evaluation methodo- logy by evaluating the strategic option as a business consideration with relevant information in a patent evaluation methodology

This article identifies and groups four broader key strategic opportunities and associated information to conduct citation-based patent evaluations. It makes four contributions. First, this article provides a citationbased patent evaluation framework synthesized from the literature. The framework provides guidance to entrepreneurs and managers and provides a framework to understand four different strategic groups of business considerations with the required interrelated categories of information. This framework enables patent evaluation from the perspectives of identifying strategic partners, strategic innovation, and inventions and strategic linkages between firms and people. Second, this article identifies and groups business considerations into the four strategic groups of business considerations. Third, this article identifies categories of prior art, patent, and business information interrelated with each strategic group of business considerations to enable the patent evaluation. Finally, it provides four recommendations to entrepreneurs and managers for identifying specific opportunities and conducting patent evaluations.

The body of this article is organized into four sections. The first section reviews the literature about citationbased patent evaluation methodologies. This section also discusses the existing citation-based patent evaluation methodologies, business opportunities, and information required to conduct an evaluation. The second section describes the proposed citation-based patent evaluation framework and provides four example scenarios where it could be applied. The third section provides recommendations for entrepreneurs and managers, and a final section concludes the article.

\section{A Review of Citation-Based Methodologies}

Patent evaluation methodologies enable the assessment of technology, patent, metadata, and business opportunities to reveal hidden details and insight. A particular type of patent evaluation methodology focuses on the prior art citations. In such evaluations, citations are used for different types of measures, depending on the business consideration.

Prior art citations identify technology that was available before the filing date of the patent application; they list what was known, or the "state of the art", prior to the invention of the new technology. These citations create a 


\section{A Citation-Based Patent Evaluation Framework}

\section{Derek Smith}

link between the prior art and the new patent application. When a prior art citation refers to an existing patent, this technology coupling or link is made explicit in the patent. The new patent application creates a formal link back in time to the prior art - this is called a "cited citation". However, the older patent also inherits a citation forward in time to the new application - this is called a "citing citation". Thus, a given patent may have cited citations (i.e., backwards in time to prior art) and the patent may also be listed in the future as a citing citation (i.e., forwards in time, meaning the older patent itself has become prior art).

The objective of this literature review is to examine the current state of knowledge in citation-based patent evaluation methodologies. The relevant literature was located using a broad keyword search of scholarly journals in the Business Source Complete database (tinyurl.com/22teqry). The keywords were a combination of: "patent", "business", "citation", "evaluation", and "valuation". This search yielded 77 potential articles published between 1993 and early 2014. The abstracts and introductions of the 77 articles were examined closely, first with a focus on prior art patent citations, and then with a narrower focus on patent evaluation methodologies that required citations, either alone or in combination with other information. This step resulted in a list of 12 relevant articles related to the topic of citation-based patent evaluation methodologies. Specifically, these articles all reported on empirical research involving a range of firms in the integrated circuit manufacturing, pharmaceutical, and patent auction industries. The list only included firms having patents in the United States and Europe, and firms having inventors in Brazil, Russia, India, and China.

The articles covered different types of citation-based patent evaluation methodologies. Bapuki, Loree, and Crossan (2011) and Deng (2008) provided an evaluation of a firm's performance based on the relationship of knowledge between the citation (old technology) and the patent (new technology). Two articles provided an evaluation of a patent portfolio: Brietzman and Thomas (2002) used patent portfolio evaluation when considering the business of mergers and acquisition targeting, and Bapuki and colleagues (2011) targeted the business consideration of joint ventures and strategic alliances between firms. Chen and Chang (2010) used patent portfolio evaluation to measure a firm's performance. Four articles provided an approach to determine patent value. Fischer and Leidinger (2014) and Nair, Mathew, and Nag (2011) evaluated the value of a patent based on a patent auction price. Hall, Jaffe, and Trajtenberg
(2005) evaluated the value of a patent based on a firm's stock market price. Harhoff, Scherer, and Vopel (2002) used survey data to evaluate patent value. Hirschey and Richardson (2004) evaluated patent quality with a firm's stock market price. Reitzig (2003) provided an evaluation for the present value of a patent. Tseng (2009) provided an evaluation to compare the level of innovation between countries.

In summary, the literature review revealed the following nine types of citation-based patent evaluations:

1. Mergers and acquisition targeting

\section{Joint venture targeting}

\section{Strategic alliance targeting}

4. Firm performance based on knowledge flow or associated with a firm's patent portfolio

5. Patent value based on a sale price or a firm's stock market price and based on a portfolio of patents

\section{Patent quality based on a portfolio of patents}

\section{Present value of a patent}

\section{A degree of invention based on a portfolio of patents}

\section{A range of comparisons based on knowledge flow}

The literature was further inductively synthesized to identify trends across the body of literature from four specific perspectives, as outlined in Table 1. A first perspective is the overall business consideration, which identified a business issue or opportunity to investigate based on an evaluation of the patent, including strategic partnerships, strategic innovations, and inventions, as well as identifying potential leads to other firms and people.

A second perspective is citation information. This perspective relates to the use of prior art citations in the evaluation of a patent and includes the cited citation list of patents and the citing citation list of patents that depend on a particular evaluation need. Every one of the business considerations requires the use of citation information in the patent evaluation.

A third perspective is business information. This perspective relates to the type and makeup of business metrics required by patent evaluations in association 


\section{A Citation-Based Patent Evaluation Framework}

\section{Derek Smith}

with the overall business considerations. Some business considerations require the additional business metrics and others do not.

A fourth perspective is patent information, which relates to metadata associated with the patent and, again, some business considerations require the additional patent metadata and others do not.

\section{Business Considerations}

Four strategic groups of business considerations were synthesized from the literature review concerning citation-based patent evaluation methodologies. Respectively, these four groups concerned the strategies to identify: business partners, strategic innovation, strategic inventions, and strategic linkages between patents.

Table 1. Citation-based patent evaluation methodologies identified in the literature review

\begin{tabular}{|c|c|}
\hline Perspective & Methodologies \\
\hline $\begin{array}{l}\text { Business } \\
\text { Contribution }\end{array}$ & $\begin{array}{l}\text { - Product portfolio management, joint ventures, and strategic alliances (Bapuki et al., 2011) } \\
\text { - Targeting and due diligence in a mergers and acquisition process to identify key inventors, technology, } \\
\text { - higher impact patents, and technological compatibility (Brietzman \& Thomas, 2002) } \\
\text { - Measuring firm performance (Chen \& Chang, 2010) } \\
\text { - Measuring economic value of knowledge spillovers (Deng, 2008) } \\
\text { - Determifying the geographic location of knowledge spillovers (Jaffe et al., 1993) } \\
\text { - Gauging a firm's inventive and innovative value (Hirschey \& Richardson, 2004) } \\
\text { - Determining the present value and inventiveness of a patent (Reitzig, 2003) } \\
\text { - Comparing innovation on a country basis to identify fundamental, applied, incremental and radical } \\
\text { innovation (Tseng, 2009) }\end{array}$ \\
\hline $\begin{array}{l}\text { Patent } \\
\text { Information }\end{array}$ & $\begin{array}{l}\text { - Patent counts, patent growth, current impact, linkage to science, technology cycle time, R\&D intensity, } \\
\text { and market to book values (stock market value) (Brietzman \& Thomas, 2002) } \\
\text { - Patent share; relative patent position (Chen \& Chang, 2010) } \\
\text { - Patent family size as a proxy for economic relevance and IPC classes as a proxy for patent scope (Fischer \& } \\
\text { Leidinger, 2014) } \\
\text { - Patent family size, opposition outcomes in Europe, and IPC classification as a proxy for scope of the } \\
\text { patent (Harhoff et al., 2002) } \\
\text { - Breadth of claims; degree of difficulty to design around; disclosure and position of a patent in a portfolio of } \\
\text { patents as a proxy for patent value (Reitzig, 2003) }\end{array}$ \\
\hline $\begin{array}{l}\text { Economic } \\
\text { Information }\end{array}$ & $\begin{array}{l}\text { - Market value; optimal value of citations can positively increase market value (Chen \& Chang, 2010) } \\
\text { - Firm performance; sales as a proxy (Bapuji et al., 2011) } \\
\text { - Market valuation (stock market value and book value); R\&D ratio (Deng, 2008) } \\
\text { - Stock market valuation of intangible assets (Hall et al., 2005) } \\
\text { - Stock market prices; number of patents; value of R\&D expenditures (Hirschey \& Richardson, 2004) } \\
\text { - Inventor and firm information as a proxy for geographic location (Jaffe et al., 1993) }\end{array}$ \\
\hline
\end{tabular}




\section{A Citation-Based Patent Evaluation Framework}

\section{Derek Smith}

Identifying strategic business partners requires the application of citation information and business economic information in the evaluation and is useful in product portfolio management, finding potential partners for joint ventures and strategic alliances (Bapuki et al., 2011), and finding potential partners based on a firm's performance (Deng, 2008).

Identifying strategic innovation requires the application of citation information, business economic information, and patent information in the evaluation. It leads to an evaluation of the patent or patents from the perspectives of intellectual property and business to reveal targets for mergers and acquisition (Brietzman \& Thomas, 2002) or the value or importance of a patent (Fischer \& Leidinger, 2014; Hall et al., 2005).

Identifying strategic inventions requires the application of citation information with patent information and leads to an evaluation of the patent or patents from an intellectual property perspective to reveal the present value of a patent (Reitzig, 2003), the degree of innovation (Tseng, 2009), or firm performance from an inventiveness perspective (Chen \& Chang, 2010).

Finally, identifying strategic linkages between patents requires citation information and leads to an evaluation of the patent or patents from a technology perspective to compare the geographic location of knowledge spillovers (Jaffe et al., 1993), country-based innovation comparisons (Tseng, 2009), the inventiveness or "simplicity" of a patent (Reitzig, 2003), or incremental versus radical innovation (Tseng, 2009).

\section{Citation Information}

Prior art citations relate to the flow or exchange of knowledge (Bapuki et al., 2011) between old technology and the new technology described in the patent. Nonpatent citations relate to a flow of knowledge between research (Hirschey \& Richardson, 2004) and the new technology described in the patent. Prior art citations also reveal the names of inventors, entrepreneurs, and firms associated with a patent (Hall et al., 2005). As described earlier, citation information may include both backwards citations (i.e., cited citations referring to earlier records; may be part of the original patent or added later) and forwards citations (i.e., citing citations referring to later records; added after the original patent application). Citation-based evaluations may use cited citations or citing citations in three different ways. First, the evaluation may be based on cited citations to understand the relationship with the old prior art. Second, the evaluation may be based on citing citations to understand the influence on the newer technology. Finally, the evaluation may be based on a combination of cited and citing citations. Through assignment of patent-ownership metadata associated with the patent, the citations also further identify when the citations are internal or external to the firm , which allows the evaluator to examine the citation relationships from the perspective of the firm or competitors to the firm.

Cited citations pertain to and indicate relative patent value (Chen \& Chang, 2010), knowledge spillovers of old technology into a new technology (Deng, 2008; Jaffe et al., 1993) and novelty or inventiveness (Reitzig, 2003). In contrast, citing citations relate to patent quality (Fischer \& Leidinger, 2004; Hirschey \& Richardson, 2004), patent value (Chen \& Chang, 2010), patent portfolio performance (Deng, 2008; Jaffe et al., 1993) and scientific advances (Hirschey \& Richardson, 2004).

\section{Business Information}

Citation information may also be supplemented with business economic information that depends on the type of business contribution from the patent evaluation methodology. For example, business economic information is required in addition to citation information when the business consideration relates to strategic partner selection or identifying strategic innovation.

Citation information is supplemented with business economic information when the business consideration from the patent evaluation methodology relates to firm performance or economic value, joint ventures, strategic alliances, or a mergers and acquisition process. Business economic information includes sales information (Bapuki et al., 2011), market valuation information (Deng, 2008), stock market information (Hall et al., 2005; Hirschey \& Richardson, 2004), and patent auction price (Fischer \& Leidinger, 2014; Nair et al., 2011).

\section{Patent Information}

Citation information may also be supplemented with other patent-related information when the business contribution from the patent evaluation methodology relates to the patent or aspects surrounding the patent. Patent related-information includes:

- the number of patents, patent portfolio growth, current patent impact, linkages to science, the technology cycle time, R\&D intensity (Brietzman \& Thomas, 2002) 


\section{A Citation-Based Patent Evaluation Framework}

\section{Derek Smith}

- the share of patents, relative patent position (Chen \& Chang, 2010)

- the patent family size and international patent classification codes (Fischer \& Leidinger, 2014)

- opposition outcomes in Europe (Harhoff et al., 2002)

- the breadth of the patent claims, the degree and difficulty to design around a patent, the patent disclosure and position of the patent in the portfolio (Reitzig, 2003)

\section{Citation-Based Patent Evaluation Framework}

Citation-based patent evaluation methodologies require a particular strategic focus. The evaluating firm must focus on a particular business consideration and provide links to relevant information. The citationbased patent evaluation framework was created through induction and synthesis of the ideas from the literature. The framework pulls all of this together with the associated linkages between the four key categories and is illustrated in Figure 1.
The citation-based patent evaluation framework synthesized in this research includes four constructs relating to citation information, business considerations, business information, and patent information. The main focus is business considerations and it connects with a subsequent citation-based patent evaluation methodology. The business considerations are grouped into four strategic groups: strategic partners, strategic innovation, strategic inventions, and strategic linkages between patents. These four strategic groups have very specific linkages and are interrelated to the information in the other three constructs as illustrated in Figure 1.

The "strategic partners" consideration relates to targeting higher-performance firms for joint ventures and strategic alliances. The evaluation requires both citation information and economic information. The "strategic innovation" consideration relates to targeting firms for a potential merger and acquisition or firms with higher-value, higher-quality patents. This type of evaluation requires citation information, economic information, and patent information. The "strategic in-

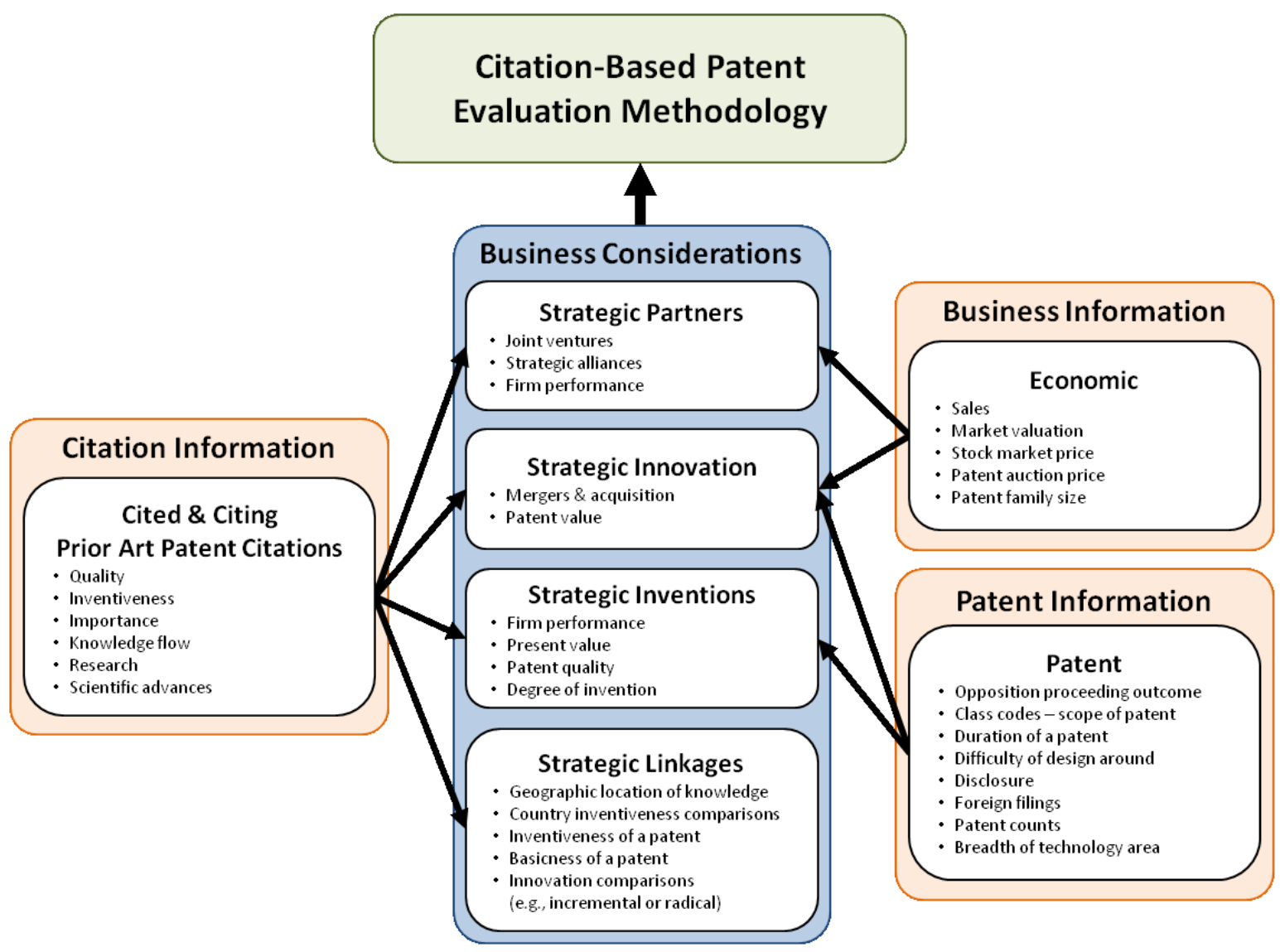

Figure 1. The citation-based patent evaluation framework 


\section{A Citation-Based Patent Evaluation Framework}

\section{Derek Smith}

ventions" consideration relates to identifying a firm's more inventive assets. This could be the evaluating firm or a competitive firm, and it requires both citation information and patent information. Finally, the "strategic linkages" consideration relates to tracking knowledge flow for a range of comparisons concerning inventiveness and identifying more inventive firms and actors. This evaluation requires citation information.

Table 2 summarizes guidance for entrepreneurs and managers in the form of a checklist. It associates a citation-based patent evaluation methodology with each of the four strategic options of a business consideration and the information required by each of the four strategic options to conduct the evaluation.

The first step for entrepreneurs and managers in proactively preparing for an evaluation of a strategic opportunity is to identify the strategic focus from the four strategic groups of business considerations. Then, they identify and gather related citation information, economic information, and patent information based on the links to the strategic groups of the business considerations. The checklist will assist with this activity. Gathering the relevant information becomes an ongoing process to prepare the firm for any eventual citation-based patent evaluation of strategic opportunities.

In the subsections that follow, four example scenarios illustrate how the business considerations from Figure 1 and Table 2 can be applied in a citation-based patent evaluation.

\section{Scenario 1: Strategic partners}

Consider a firm that is interested in joining a business ecosystem and is seeking to identify a strategic partner from the firms in this ecosystem. This evaluation requires both citation information and economic information. First, the evaluating firm should identify the patent or patents of the target firms. Second, the firm should acquire the citation information, including the names of the inventors and associated firms. The citation information reveals whether the patents are based on knowledge that is internal or external to the firms. A patent based primarily on internal firm citation information suggests the associated firm has a higher capability for inventiveness. Next, the evaluating firm should acquire economic information is the form of sales information for the technology associated with the patent. Finally, the information may be compared on a firm-by-firm basis to identify target firms with higher or lower capability of inventiveness and higher or lower commercial success.

\section{Scenario 2: Strategic innovation}

Or, perhaps a publically traded company is interested in identifying a strategic innovation, either one of its own or that of a competitor. This evaluation requires citation, economic, and patent information. Again, the first steps are to identify the patent or patents of interest and then acquire the citation information. In this scenario, citation information includes the list of cited citations, the list of citing citations, and the date of the citations (older vs. newer). The citation information also includes the number of cited citations that are scientific, which reveals the degree to which the patent is based on scientific research or an early-commercialized technology. The number of citing citations reveals the degree of future value where the higher the number of citing citations, the higher the future value of the patent.

Finally, the company should acquire stock market information and the expenditure of the research and development efforts and the size or number of patents in the patent portfolio. The goal is to find the patents that have the highest number of citing citations based on scientific research and that are associated with the best economic information. This combination of information can reveal the strategic innovations.

\section{Scenario 3: Strategic inventions}

Consider a firm that is interested in identifying a relatively higher present value patent from a selection of patents that has not been commercialized. This evaluation requires both citation and patent information, so the firm should start by identifying the patent or patents of interest and gather cited citation information. A high number of cited citations suggests low inventiveness. Next, the firm should review the breadth of the claims in the patent and consider how easy it would be to "design around" the patent. The patent disclosure should be reviewed from a competitive perspective to assess the learning value to competitors. Finally, the relative value of the patent in a portfolio of patents should be examined. Conducting this type of evaluation on a patentby-patent basis provides a relative comparison of the technological present value of the patent and helps identify strategic inventions with higher present value.

\section{Scenario 4: Strategic linkages}

Finally, consider a firm that is contemplating breaking into a new technology domain. Identifying strategic linkages based on the flow of knowledge between patents can help identify actors and firms associated with particular technology groups identified in the patents. So, the first step is to identify the key patents for evaluation. Then, both the cited citation and citing citation informa- 


\section{A Citation-Based Patent Evaluation Framework}

\section{Derek Smith}

Table 2. Business consideration and information category checklist

\begin{tabular}{|c|c|c|c|c|}
\hline \multirow[b]{2}{*}{ Citation-Based Patent Evaluation Methodology } & \multirow[b]{2}{*}{$\begin{array}{c}\text { Business } \\
\text { Consideration }\end{array}$} & \multicolumn{3}{|c|}{ Information } \\
\hline & & $\begin{array}{l}\text { Prior Art } \\
\text { Citation }\end{array}$ & Business & Patent \\
\hline $\begin{array}{l}\text { Breitzman and Thomas (2002) describe a method for evaluating a patent } \\
\text { from the perspective of targeting firms for potential mergers and } \\
\text { acquisitions. The method evaluates patent counts, patent growth, } \\
\text { current impact, science linkages, technology cycle time, and } R \& D \\
\text { intensity with market to book values and stock market value. }\end{array}$ & $\begin{array}{l}\text { Strategic } \\
\text { Innovation }\end{array}$ & $\checkmark$ & $\checkmark$ & $\checkmark$ \\
\hline
\end{tabular}

Fischer and Leidinger (2014), Hall et al. (2005), Harhoff et al. (2002), and Nair et al. (2011) describe a method for evaluating a patent from the perspective of patent value. The methods evaluate auction data, patent quality (citing citations), economic relevance (family size), patent scope (IPC codes), stock market price, non-patent literature, outcome of opposition proceedings, and patent family size.

\section{Strategic} Innovation
Hirschey and Richardson (2004) describe a method for evaluating patent quality. The method evaluates patent quality (citing citations) and stock market price, number of patents, and R\&D expenditures.
Strategic Innovation
Bapuki et al. (2011) describe a method for evaluating a patent from the perspective of a joint venture or strategic alliance targeting. The method evaluates internal knowledge, external knowledge, and sales information. External knowledge was found to have a negative effect on firm performance.
Strategic

Partners
Deng (2008) describes a method for evaluating firm performance. The method evaluates knowledge (citied citations), importance (citing citations), stock market value, and book value.
Strategic Partners
Chen and Chang (2010) describe a method for evaluating firm performance. The method evaluates patent share, relative patent position, and knowledge.
Strategic Invention

Reitzig (2003) describes a method for evaluating a patent portfolio from the perspective of present value. The method evaluates the life of a patent, inventiveness (citied citations), breadth of claims, degree of difficulty to design around, the disclosure, position of a patent in a portfolio, and knowledge.

Strategic Invention
Tseng (2009) describes a method for evaluating the degree of innovation. The method evaluates quality (cited citations) and IPC codes.

Jaffe et al. (1993) describe a method for evaluating knowledge. The method evaluates patent citations (cited citations) from a knowledgeflow perspective in a citation network.
Strategic Invention 


\section{A Citation-Based Patent Evaluation Framework}

\section{Derek Smith}

tion should be obtained, including the names of the inventors and the names of the firms. Finally, for each key patent, links between the citations should be revealed and the actors and firms associated with each key patent should be identified.

\section{Recommendations for Entrepreneurs and Managers}

From a close reading of the published research on citation-based patent evaluation methodologies, and through induction and synthesis looking closely at business considerations, related information, and linkages between the business considerations and information, four recommendations are offered for entrepreneurs and mangers seeking to be prepared for strategic opportunities and business decisions by revealing valuable hidden details and insight surrounding a patent.

\section{Make citation-based patent evaluation a differentiating business practice.}

Citation-based patent evaluation methodologies provide an interesting opportunity to gain strategic advantage. This strategic advantage could relate to a firm's patent or portfolio of patents, or it could be with respect to another firm's patent or portfolio of patents. This competitive aspect is not well understood or known by entrepreneurs and managers; however, it can provide a strategic advantage to firms that identify and target strategic partners, innovation, inventions, and linkages in the citation network. This competitive aspect can become a differentiating business practice, thereby bringing strategic advantage to the firm.

\section{Identify, understand, and use the four strategic options for citation-based patent evaluations.}

The strategic options synthesized from a review of the extant literature with respect to business considerations reveals options that may be leveraged with specific interrelated information. Seeking out strategic partners, innovation, inventions and linkages provides relevant strategic advantage to a firm. Citation-based patent evaluation provides the means to realize this competitive advantage based on the citations, business economic, and patent information.

\section{Make the gathering of patent evaluation information a core patent management activity.}

The citation-based patent evaluation framework and checklist help identify the strategic options and key sources of information required by each option. Gather relevant information relevant to the opportunity based on these strategic options as part of a management pro- cess or activity. This prepares the firm for the moment when a patent evaluation is required.

\section{Understand how to combine strategic options with rel- evant information.}

The citation-based patent evaluation framework reveals specific links between the strategic options and the required interrelated categories of information. First, identify the strategic option and then gather the interrelated information. Finally, conduct the citation-based patent evaluation based on the literature identified in Table 2.

In summary, a key to the firm's success is leveraging the strategic options from the business considerations and interrelated information about the citations, business, and patents to reveal the hidden details surrounding their patent, or a competitor's patent, and make better strategic business decisions.

\section{Conclusion}

The citation-based patent evaluation framework and checklist that emerged from this research provide guidance and reveal the requirements for a set of nine different patent evaluation methodologies. The requirements are based on the four static options of business considerations, the information required by each consideration, and the associated links between the options and information to prepare for an evaluation.

Entrepreneurs and managers are able to prepare for strategic opportunities that include either a firm's patent or a competitive patent against the firm. They can identify strategic options, identify relevant information interrelated to the strategic options, and proactively gather this relevant information over time. This approach provides early and ongoing insight that enables strategic opportunities and decisions.

Further research should focus on refining the current strategic options and interrelated information, and expanding the citation-based patent evaluation framework. The research should examine other citation-based patent evaluation methodologies, business considerations, the interrelated information, and specifically the links between the considerations and interrelated information.

In practice, entrepreneurs and managers should identify their strategic options and proactively gather the information required by these options to reveal the valuable hidden details that enable strategic business decisions. 


\section{A Citation-Based Patent Evaluation Framework}

\section{Derek Smith}

\section{About the Author}

Derek Smith is the founder and principal of Magneto Innovention Management, an intellectual property consulting firm that assists entrepreneurs and small businesses with difficult intellectual property issues. $\mathrm{He}$ is a registered patent agent in both Canada and the United States, and he has over 20 years of experience working as an intellectual property management consultant and patent agent for IBM Canada, Bell Canada, and Husky Injection Molding Systems where he was Director of Global Intellectual Property. Prior to entering the field of intellectual property, he was an advisory engineer at IBM Canada where he was involved in a variety of leading-edge software development projects. Derek holds an MASc degree Technology Innovation Management from Carleton University in Ottawa, Canada , for which he was awarded a Senate Medal for Outstanding Academic Achievement. Derek also holds a BEng degree in Systems and Computer Engineering, also from Carleton University.

Citation: Smith, D. 2014. A Citation-Based Patent Evaluation Framework to Reveal Hidden Value and (cc) BY Enable Strategic Business Decisions. Technology Innovation Management Review, 4(6): 4-13.

http://timreview.ca/article/799

Keywords: intellectual property, patent, patent citations, prior art citation, patent value, patent evaluation, citation-based patent evaluation, literature review

\section{References}

Bapuki, H., Loree, D., \& Crossan. M. 2011. Connecting External Knowledge Usage and Firm Performance: An Empirical Analysis. Journal of Engineering and Technology Management, 28(4): 215-231.

http://dx.doi.org/10.1016/j.jengtecman.2011.06.001

Breitzman, A., \& Thomas, P. 2001. Using Patent Citation Analysis to Target/Value M\&A Candidates. Research-Technology Management, 35(5): 28-36.

Chen Y., \& Chang, K. 2010. Exploring the Nonlinear Effects of Patent Citations, Patent Share and Relative Patent Position on Market Value in the US Pharmaceutical Industry. Technology Analysis \& Strategic Management, 22(2): 153-169. http://dx.doi.org/10.1080/09537320903498496

Deng, Y. 2008. The Value of Knowledge Spillovers in the U.S. Semiconductor Industry. International Journal of Industrial Organization, 26(4): 1044-1058. http://dx.doi.org/10.1016/j.ijindorg.2007.09.005

de Wilton, A. 2011. Patent Value: A Business Perspective for Technology Startups. Technology Innovation Management Review, 1(3): 5-11. http://timreview.ca/article/501

Fischer, T., \& Leidinger, J. 2014. Testing Patent Value Indicators on Directly Observed Patent Value - An Empirical Analysis of Ocean Tomo Patent Auctions. Research Policy, 43(3): 519-529.

Hall, B. H., Jaffe, A., \& Trajtenberg, M. 2005. Market Value and Patent Citations. RAND Journal of Economics, 36(1): 16-38. http://www.jstor.org/stable/1593752

Haroff, D., Scherer, F. M., \& Vopel, K. 2003. Citations, Family Size, Opposition and the Value of Patent Rights. Research Policy, 32(8): 1343-1363.

http://dx.doi.org/10.1016/S0048-7333(02)00124-5

Hirschey, M., \& Richardson, V. 2003. Are Scientific Indicators of Patent Quality Useful to Investors? Journal of Empirical Finance, 11(1): 91-107.

http://dx.doi.org/10.1016/j.jempfin.2003.01.001

Jaffe, A. B., Trajtenberg, M., \& Henderson R. 1993. Geographic Localization of Knowledge Spillovers as Evidenced by Patent Citations. Quarterly Journal of Economics, 108(3): 577-598. http://dx.doi.org/10.2307/2118401

Nair, S. S., Mathew, M., \& Nag, D. 2011. Dynamics between Patent Latent Variables and Patent Price. Technovation, 31(12): 648-654. http://dx.doi.org/10.1016/j.technovation.2011.07.002

Reitzig, M. 2003. What Determines Patent Value? Insights From the Semiconductor Industry. Research Policy, 32(1): 13-26. http://dx.doi.org/10.1016/S0048-7333(01)00193-7

Tseng, C. 2009. Technological Innovation in the Bric Economies. Research and Technology Management, 52(2): 29-35. 